\title{
Identification, Characterization, and Relatedness of Luteovirus Isolates from Forage Legumes
}

\author{
V. D. Damsteegt, A. L. Stone, A. J. Russo, D. G. Luster, F. E. Gildow, and O. P. Smith
}

First, second, and fourth authors: USDA-ARS, NAA, Foreign Disease-Weed Science Research Unit, Fort Detrick, MD 21702; third author: Mount St. Mary's College, Emmitsburg, MD 21727; fifth author: Department of Plant Pathology, Pennsylvania State University, University Park 16801; and sixth author: Department of Biology, Hood College, Frederick, MD 21701. Accepted for publication 28 January 1999.

\begin{abstract}
Damsteegt, V. D., Stone, A. L., Russo, A. J., Luster, D. G., Gildow, F. E., and Smith, O. P. 1999. Identification, characterization, and relatedness of luteovirus isolates from forage legumes. Phytopathology 89:374-379.

Virus isolates from forage legumes collected from eight different states were identified as luteoviruses closely related to soybean dwarf luteovirus dwarfing (SbDV-D) and yellowing (SbDV-Y) described in Japan. All isolates produced reddened leaf margins in subterranean clover and were transmitted in a persistent manner by Acrythosiphon pisum, but not

SbDV-Y were differentially reactive with endemic isolates. Immunoblots probed with a SbDV-D polyclonal antiserum showed single 26-kDa coat protein bands, confirming close serological relatedness to SbDV. Analyses of genomic and subgenomic double-stranded RNAs and northern blot analyses confirmed genomic relatedness to SbDV. Based on our results, we conclude that the U.S. luteovirus isolates studied comprise a strain or strains of the soybean dwarf virus that have clovers as common hosts and the pea aphid as a common vector.
\end{abstract} by Aulacorthum solani. Specific monoclonal antibodies raised against
Additional keywords: vector-specific strains.
Soybean dwarf, first described as a virus disease of soybean (Glycine $\max$ (L.) Merr.) in Japan (36), is capable of causing serious yield losses in soybean $(35,37)$. Two strains of the soybean dwarf luteovirus (SbDV), dwarfing (-D) and yellowing (-Y), were identified by Tamada (34) based on host range and symptoms in soybean. The SbDV-D and SbDV-Y strains, persistently aphid-transmitted by the foxglove aphid (Aulacorthum solani (Kaltenbach)) (33), are closely related serologically and have been reported to occur naturally in Japan only (5). Electron micrographs of infected soybean tissue have revealed high concentrations of virions only in phloem tissue (30).

A closely related virus reported from Australasia as subterranean clover red leaf virus (SCRLV) $(17,40)$ was renamed SbDV on the basis of biological and serological relatedness (15). The latter consists of isolates transmitted by A. solani or Acyrthosiphon pisum (Harris) (13). In 1983, a SbDV-like (SCRLV-like) pathogen was isolated from legumes in California (14) that reacted with SbDV antisera and was persistently transmitted by Acyrthosiphon pisum. Subsequently, SbDV-like isolates have been reported from naturally infected, asymptomatic white clover (Trifolium repens $\mathrm{L}$.), symptomatic red clover (T. pratense L.), alsike clover (T. hybridum L.), subterranean clover (T. subterraneum L.), and soybean ( $G$. max) from 11 eastern and southeastern states in the United States $(7,24)$. An isolate of SbDV infecting lentils was recently reported from Syria (21). We report here the biological and physicochemical characterization of several endemic U.S. isolates and compare them with known SbDV strains. Preliminary reports on this research have been published $(6-8,29)$.

Corresponding author: V. D. Damsteegt; E-mail address: damsteeg@ncifcrf.gov

Publication no. P-1999-0310-01R

This article is in the public domain and not copyrightable. It may be freely reprinted with customary crediting of the source. The American Phytopathological Society, 1999

\section{MATERIALS AND METHODS}

Virus isolates. SbDV-D and SbDV-Y were obtained from T. Tamada (Naganuma, Japan) and maintained in soybean 'Williams' through serial aphid transmissions with A. solani. Additional strains of SbDV were obtained from New Zealand (SbDV-NZ; J. W. Ashby, Christchurch, New Zealand) and Tasmania (SbDV-TAS; G. R. Johnstone, Hobart, Tasmania) and maintained in subterranean clover. Bean leaf roll virus (BLRV) was obtained from R. Hampton (Agricultural Research Service [ARS], Corvallis, OR) and maintained in Pisum sativum L. cv. Puget $(1,2)$. Endemic isolates were obtained from asymptomatic white clover from Kentucky (KY; S. A. Ghabrial), Mississippi (MS; M. R. McLaughlin), North Carolina (NC; C. L. Campbell), South Carolina (SC; O. W. Barnett), and Maryland (MD-1 and MD-2); alsike clover from Pennsylvania (PA); red clover from New York (NY); and subterranean clover from Virginia (VA 20; S. A. Tolin). All endemic isolates were maintained in 'Mount Barker' subterranean clover through serial aphid transmissions with Acyrthosiphon pisum.

Aphid vectors. Colonies of $A$. solani were maintained on curly dock (Rumex crispus L.). Acyrthosiphon pisum was obtained from R. Hampton and maintained on broad bean (Vicia faba L.). All aphid species were monitored periodically to insure colonies were free of any contaminant viruses. The identity of each aphid population was verified by M. Stoetzel (ARS Systematic Entomology Laboratory, Beltsville, MD).

Aphid populations were tested for their ability to transmit known strains of $\mathrm{SbDV}$ and the endemic forage legume isolates by placing 50 to 500 aphids on infected clover or soybean leaflets for a 48 -h acquisition access period (AAP), followed by a 48-h inoculation access period (IAP), on healthy 3-week-old subterranean clover seedlings utilizing 20 or more aphids per seedling. Seedlings were sprayed with a solution of Malathion (0,0-dimethyl phosphorodithioate of diethylmercapto succinate; $0.2 \mathrm{~g}$ a.i./liter) to remove the aphids and placed on glasshouse benches for 30 days at 20 to $25^{\circ} \mathrm{C}$ for symptom development. 
Purification. Endemic virus isolates were purified from 'Puget' pea by an enzyme extraction method similar to that previously described for SbDV $(12,19)$. Modifications of the SbDV purification protocol were the use of $100 \mathrm{mM}$ sodium citrate extraction buffer with $10 \mathrm{~mm}$ EDTA, $\mathrm{pH} 8$; precipitation of chloroform/butanol-clarified supernatant with $8 \%$ polyethylene glycol 6000 (PEG) with $1 \%$ $\mathrm{NaCl}$; and centrifugation of the resuspended high-speed pellets on a $30 \%$ sucrose pad $(9,26)$. The resultant pellets were resuspended overnight at $4^{\circ} \mathrm{C}$ in $1.0 \mathrm{ml}$ of $10-\mathrm{mm}$ sodium phosphate, $\mathrm{pH} 7.6$. Virus preparations were layered onto 10 to $40 \%$ sucrose gradients and centrifuged in an SW 41 rotor (Beckman Instruments, Inc., Palo Alto, CA) at $248,000 \times g$ for $2 \mathrm{~h}$. Gradients were scanned with an ISCO UA-5 absorbance monitor at $254 \mathrm{~nm}$ (ISCO, Lincoln, $\mathrm{NE}$ ). Absorption peak fractions were collected, concentrated by centrifugation in a type 75 Ti rotor (Beckman Instruments, Inc.) at $223,000 \times g$ for $1 \mathrm{~h}$, resuspended in $250 \mu \mathrm{l}$ of resuspension buffer for at least $3 \mathrm{~h}$, and then stored frozen at -20 or $-80^{\circ} \mathrm{C}$.

Electron microscopy. Purified virus preparations of endemic isolates were used to determine virion morphology and size by transmission electron microscopy. Formvar carbon-coated 300-mesh grids were incubated on 20- $\mu \mathrm{l}$ drops of virus preparations for $5 \mathrm{~min}$, rinsed twice with distilled water, incubated 3 min on $2 \%$ aqueous uranyl acetate, and air-dried. Grids were examined at a magnification of 30 to $50 \mathrm{~K}$ on a JEOL 1200 TEM (JEOL USA, Inc., Peabody, MA) at the Biotechnology EM Facility for the Life Sciences, Pennsylvania State University (State College, PA). Particle size was determined by measuring the diameter of 50 virions on photographic plates and calculating the mean diameter.

To examine plant tissues for virus localization, young 'Mount Barker' leaf tissue infected with endemic isolates and exhibiting mild reddening symptoms and 'Williams' soybean leaves infected with SbDV-Y were cut into 1- to 2-mm slices while submerged in fixative consisting of $1 \%$ formaldehyde and $2 \%$ glutaraldehyde in 2-mm sodium cacodylate buffer $(\mathrm{pH} 7.5)$. The fixative was infiltrated under vacuum for $5 \mathrm{~min}$, and the tissue was allowed to fix at atmospheric pressure for $2 \mathrm{~h}$ at $4^{\circ} \mathrm{C}$. Following three buffer rinses, the tissues were postfixed in $1 \%$ osmium tetroxide, dehydrated in acetone, and embedded in an eponaraldite plastic. Ultrathin sections of leaf mesophyll and vascular bundles were stained for $30 \mathrm{~min}$ in $2 \%$ uranyl acetate/isobutanol (9:1) and $15 \mathrm{~min}$ in $0.4 \%$ lead citrate and examined for the presence of virions.

Infectivity. Virions of each endemic isolate were resuspended in purification buffer amended with sucrose to make an $18 \%$ sucrose/virus preparation. Each preparation (3 to $5 \mathrm{ml}$ ) was placed between two stretched Parafilm membranes. Nonviruliferous Acyrthosiphon pisum were allowed a 48-h AAP on the membrane, after which, groups of 10 or more aphids were transferred to 'Mount Barker' seedlings for a 48-h IAP. The aphids were killed and the plants placed in the glasshouse for 30 days at 20 to $25^{\circ} \mathrm{C}$ for symptom development.

Host range. Initial transmissions of virus isolates were accomplished with Acyrthosiphon pisum to 'Mount Barker'. Development of symptoms in 'Mount Barker' and positive enzyme-linked immunosorbent assay (ELISA) were criteria for selection of isolates for further study. All host-range studies were conducted with Acyrthosiphon pisum, utilizing 10 or more aphids per test plant with 48-h AAPs and IAPs. Seed for test plant species was obtained from U.S. Department of Agriculture Regional Plant Introduction Stations and colleagues.

Serological assays. Plant tissue samples of the original isolates, greenhouse-propagated plant tissue, and purified virions were tested in double-antibody sandwich (DAS)-ELISA $(3,4,11)$ using polyclonal antisera to SbDV-D, SbDV-Y, BLRV (produced at the U.S. Army Medical Research Institute of Infectious Diseases, Fort Detrick, Frederick, MD), and beet western yellows virus (BWYV; Agdia, Inc., Elkart, IN). Monoclonal antibodies (MAbs) to highly purified whole virions of SbDV-Y were produced by standard procedures $(10,18,29)$. The MAbs were screened against SbDV-D,
SbDV-Y, BLRV, BWYV, and brome mosaic bromovirus (BMV) to select MAbs specific for SbDV. Triple-antibody sandwich (TAS)ELISA (22) was used to determine the presence of common epitopes among the endemic isolates, SbDV-D, and SbDV-Y. All TASELISA volumes were $150 \mu \mathrm{l}$ per well in Maxisorp microplates (A/S Nunc, Kamstrup, Denmark), and plates were read at $405 \mathrm{~nm}$ using a Molecular Devices V-Max Reader (Molecular Devices Corp., Menlo Park, CA).

Immunoblot analysis. Extracts from sucrose gradient-purified luteovirus preparations (12), representing $2 \mu \mathrm{g}$ of SbDV-D, SbDV-Y, MD-2, and VA 20 and $4 \mu \mathrm{g}$ of BLRV and BWYV, were resuspended in Laemmli sample buffer (20) and electrophoresed on 4 to $20 \%$ acrylamide gradient sodium dodecyl sulfate-polyacrylamide gel electrophoresis (SDS-PAGE) minigels using Laemmli buffers. Proteins were transferred to nitrocellulose membranes (pore size, $0.2 \mu \mathrm{M}$ ) in transfer buffer (38) at $10 \mathrm{~V}$ for $15 \mathrm{~h}$. After transfer, blots were blocked in 3\% (wt/vol) gelatin in Tris-buffered saline (TBS;

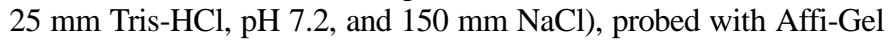
blue-purified (12) anti-SbDV-D polyclonal immunoglobulin $\mathrm{G}$ (IgG) for $3.5 \mathrm{~h}$ at $25^{\circ} \mathrm{C}$ on a shaker at $50 \mathrm{rpm}$. Following incubation with the antisera, blots were washed in TBS and probed with goat anti-rabbit IgG conjugated to alkaline phosphatase at 1:3,000 dilution. Avidin conjugated to alkaline phosphatase was included at 1:3,000 dilution to detect biotinylated molecular weight standards and detected with kit reagents according to the manufacturer's protocols (Bio-Rad Laboratories, Richmond, CA).

Double-stranded (ds) RNA analysis. Virus-infected 'Mount Barker' clover or 'Puget' pea tissue was harvested 20 to 22 days after inoculation and processed immediately for dsRNA extraction. PAGE of dsRNA and northern blot hybridization analysis were conducted as described $(25,32)$. A SbDV-Y plasmid (pSbDV-Y13), containing a 2.2-kilobase pair (kbp) cDNA downstream from the coat protein gene but including the readthrough protein gene and the $3^{\prime}$ untranslated region of the SbDV-Y genome, was used as a hybridization probe (31). Single-stranded RNA size markers (Gibco BRL, Gaithersburg, MD) were detected by hybridization to lambda DNA.

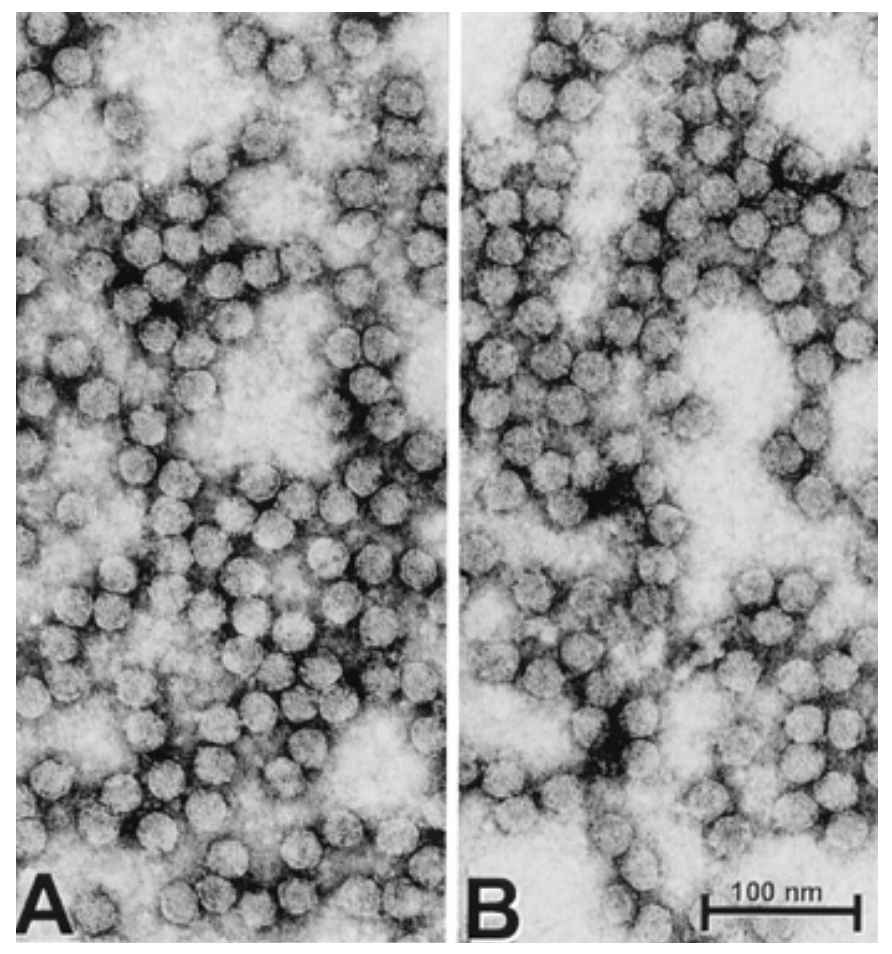

Fig. 1. Virions from purified preparations of soybean dwarf luteovirus $(\mathrm{SbDV})$ stained with $2 \%$ uranyl acetate, magnified $\times 150,000$. A, SbDV-Y (yellowing) and B, SbDV-US (United States; VA 20 isolate). Bar $=100 \mathrm{~nm}$. 


\section{RESULTS}

Purification. Initial attempts to purify the endemic SbDV isolates from subterranean clover tissue were unsuccessful. Bioassays of intermediate purification steps indicated the presence of infectious virions; however, no virus pellets were observed in high-speed preparations. Increasing the $\mathrm{pH}$ of the extraction buffer to $\mathrm{pH} 8$, changing the extraction buffer from sodium phosphate to sodium citrate, and incorporating a PEG precipitation step produced yields

TABLE 1. Determination of specificity of monoclonal antibodies (MAbs) raised to the yellowing strain of soybean dwarf luteovirus (SbDV-Y) using indirect enzyme-linked immunosorbent assay

\begin{tabular}{llll}
\hline & \multicolumn{3}{c}{ SbDV-Y MAbs } \\
\cline { 2 - 4 } Virus isolate $^{\mathrm{a}}$ & \multicolumn{1}{c}{$1 \mathrm{C} 9$} & \multicolumn{1}{c}{$1 \mathrm{C} 6$} & \multicolumn{1}{c}{$1 \mathrm{~F} 8$} \\
\hline SbDV-Y & $3.317 \pm 0.01^{\mathrm{b}}$ & $3.659 \pm 0.02$ & $3.804 \pm 0.19$ \\
SbDV-D & $3.494 \pm 0.17$ & $3.548 \pm 0.08$ & $3.530 \pm 0.21$ \\
BLRV & $0.013 \pm 0.00$ & $0.037 \pm 0.00$ & $0.041 \pm 0.01$ \\
BWYV & 0.00 & $0.001 \pm 0.00$ & $0.002 \pm 0.00$ \\
PLRV & $0.010 \pm 0.01$ & $0.013 \pm 0.00$ & $0.003 \pm 0.01$ \\
BMV & $0.007 \pm 0.00$ & $0.017 \pm 0.01$ & 0.00 \\
Buffer blank & 0.00 & 0.00 & 0.00 \\
\hline
\end{tabular}

a SbDV-D = soybean dwarf luteovirus, dwarfing; BLRV = bean leaf roll luteovirus; $\mathrm{BWYV}=$ beet western yellows luteovirus; PLRV = potato leaf roll luteovirus; and $\mathrm{BMV}=$ brome mosaic bromovirus.

b Average absorbance values $\left(A_{405}\right)$ for duplicate wells ( $200 \mathrm{ng}$ of purified virus per well). Monoclonal antibodies screened against healthy soybean with no cross-reactivity.

TABLE 2. Reactivity of soybean dwarf virus (SbDV) monoclonal antibodies (MAbs) to exotic and endemic luteovirus isolates from forage legumes by triple-antibody sandwich enzyme-linked immunosorbent assay

\begin{tabular}{|c|c|c|c|c|}
\hline \multirow[b]{2}{*}{ Isolate $^{\mathrm{a}}$} & \multirow[b]{2}{*}{ Polyclonal capture antiserum } & \multicolumn{3}{|c|}{ SbDV MAbs } \\
\hline & & $1 \mathrm{C} 9$ & $1 \mathrm{C} 6$ & $1 \mathrm{~F} 8$ \\
\hline \multirow[t]{2}{*}{ SbDV-Y } & SbDV-D & $++++^{b}$ & +++ & +++ \\
\hline & SbDV-Y & +++ & + & + \\
\hline \multirow[t]{2}{*}{ SbDV-D } & SbDV-D & ++++ & +++ & +++ \\
\hline & SbDV-Y & +++ & ++ & ++ \\
\hline \multirow[t]{2}{*}{ SbDV-NZ } & SbDV-D & ++++ & ++++ & +++ \\
\hline & SbDV-Y & +++ & ++ & + \\
\hline \multirow[t]{2}{*}{ SbDV-TAS } & SbDV-D & +++ & ++ & + \\
\hline & SbDV-Y & ++ & + & \pm \\
\hline \multirow[t]{2}{*}{ MD- $1^{\mathrm{c}}$} & SbDV-D & +++ & \pm & - \\
\hline & SbDV-Y & ++ & - & - \\
\hline \multirow[t]{2}{*}{ MD-2 } & SbDV-D & +++ & + & \pm \\
\hline & SbDV-Y & +++ & + & - \\
\hline \multirow[t]{2}{*}{ VA 20} & SbDV-D & +++ & + & \pm \\
\hline & SbDV-Y & ++ & \pm & - \\
\hline \multirow[t]{2}{*}{ MS } & SbDV-D & +++ & \pm & - \\
\hline & SbDV-Y & ++ & - & - \\
\hline \multirow[t]{2}{*}{ NY } & SbDV-D & - & + & + \\
\hline & SbDV-Y & - & + & + \\
\hline \multirow[t]{2}{*}{ PA } & SbDV-D & +++ & + & - \\
\hline & SbDV-Y & +++ & + & - \\
\hline \multirow[t]{2}{*}{$\mathrm{SC}$} & SbDV-D & ++ & \pm & - \\
\hline & SbDV-Y & ++ & \pm & - \\
\hline \multirow[t]{2}{*}{$\mathrm{NC}$} & SbDV-D & ++ & \pm & - \\
\hline & SbDV-Y & ++ & \pm & - \\
\hline \multirow[t]{2}{*}{ BLRV } & SbDV-D & - & - & - \\
\hline & SbDV-Y & - & - & - \\
\hline \multirow[t]{2}{*}{ Healthy soybean } & SbDV-D & - & - & - \\
\hline & SbDV-Y & - & - & - \\
\hline
\end{tabular}

${ }^{a}$ SbDV-Y = yellowing; SbDV-D = dwarfing; $-\mathrm{NZ}=$ New Zealand; $-\mathrm{TAS}=$ Tasmania; MD-1 and MD-2 = isolates from white clover from Maryland; VA 20 isolates from Virginia; $\mathrm{MS}=$ isolates from Mississippi; $\mathrm{NY}=$ isolates from New York; PA = isolates from Pennsylvania; $\mathrm{SC}=$ isolates from South Carolina; $\mathrm{NC}=$ isolates from North Carolina; and BLRV = bean leaf roll luteovirus.

${ }^{\mathrm{b}}$ Scale (absorbance units at $A_{405}$ ): $-=0$ to $0.2, \pm=0.2$ to $0.5,+=0.5$ to 1.0 , $++=1.1$ to $2.0,+++=2.1$ to 3.0 , and $++++=3.1$ to 4.0 .

${ }^{c}$ Endemic isolates show reactivity to a lesser extent than characterized SbDV strains. ranging from 100 to $200 \mu \mathrm{g}$ of infectious virions per $\mathrm{kg}$ of plant tissue for all isolates.

Each isolate sedimented as a single component band in sucrose gradients. Gradient fractions containing virus were collected at a depth of 5.5 to $6 \mathrm{~cm}$, which corresponded to the narrow peaks obtained by ultraviolet scanning of the gradients.

Electron microscopy. Purified preparations of endemic SbDV isolates and SbDV-Y contained isometric virions of similar morphology with mean diameters of 25 to $26 \mathrm{~nm}$ (Fig. 1). Virions were detected in leaf tissues of subterranean clovers infected with endemic isolates and showing leaf-margin reddening. High concentrations of virions were observed in a few phloem sieve elements and companion cells of vascular bundles, but not in xylem parenchyma or leaf mesophyll cells of diseased plants.

Infectivity assays. 'Mount Barker' test plants inoculated with partially purified preparations of isolates MD-1, MD-2, VA 20, MS, NY, PA, SC, or NC, which had been acquired by A. pisum through stretched Parafilm membranes, developed leaf-reddening symptoms 13 to 15 days after inoculation. Symptoms were identical with those produced by the original isolates in 'Mount Barker' clover.

Host range. All endemic virus isolates induced reddening of leaf margins in 'Mount Barker' subterranean clover; chlorotic mosaic, slight stunting, and premature desiccation of leaf margins in 'Puget' pea; mild chlorotic mottling and growth reduction in 'Williams' soybean; and no symptoms in 'Ladino' white clover. The symptoms were more pronounced on the upper surface of initial leaves produced after infection; later leaves exhibited almost no reddening. Symptom expression in 'Mount Barker' was less for PA and NY isolates compared with the others. All isolates induced leafmargin reddening and stunting in 'Crimson' clover (T. incarnatum L.) and alsike clover; slight reddening in red clover leaves; interveinal chlorosis in fava bean ( $V . f a b a)$ leaves; reddened and yellowed leaflets and slight stunting in lentils (Lens culinaris Medik. cv. Laird); and slight chlorosis in peanuts (Arachis hypogaea L. cv. Florunner).

Vectors. All luteovirus isolates of U.S. origin were transmitted by Acyrthosiphon pisum from any known susceptible host to any susceptible test host on which Acyrthosiphon pisum would feed and none were transmitted by A. solani. SbDV-D and SbDV-Y were never transmitted by Acyrthosiphon pisum.

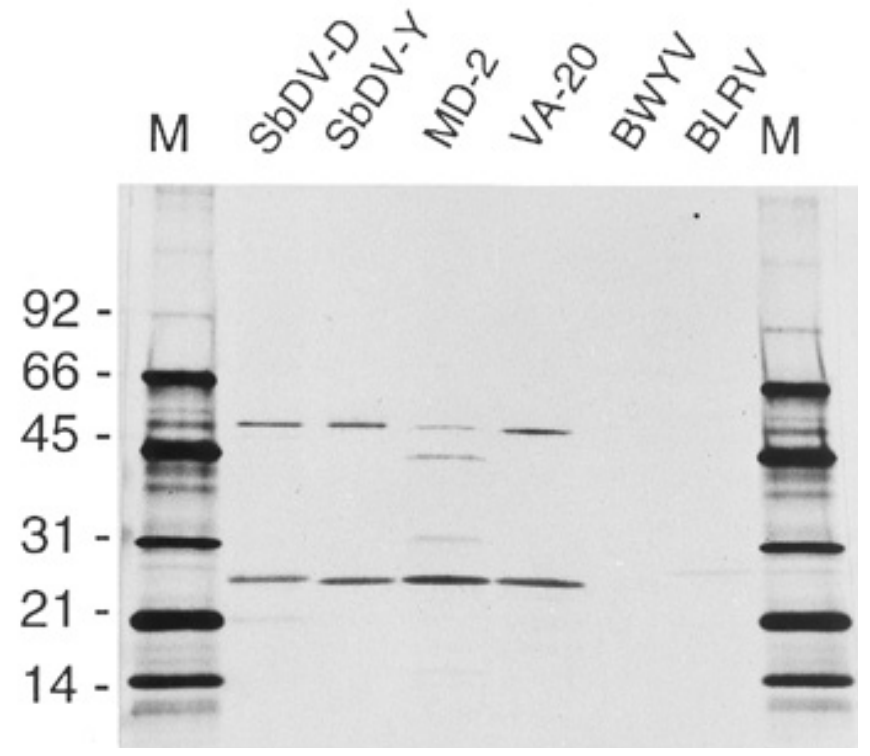

Fig. 2. Immunoblot analysis using a polyclonal antiserum prepared to soybean dwarf luteovirus, dwarfing (SbDV-D). Molecular weight (M) markers are in outside lanes. SbDV-Y = soybean dwarf luteovirus, yellowing; MD-2 = isolate from Maryland and VA $20=$ isolate from Virginia. Lanes 1 and 2, Type strains; lanes 3 and 4, endemic isolates; and lanes 5 and 6, beet western yellows (BYWV) and bean leaf roll luteoviruses (BLRV), respectively. 
Serological assays. Polyclonal antisera produced against SbDV-D and SbDV-Y virions did not differentiate among known strains of SbDV. There was slight cross-reactivity with BLRV (Fig. 1). We produced several MAbs to highly purified whole virions of SbDV-Y. Three MAbs (designated 1C9, 1C6, and 1F8) reacted strongly to SbDV-D, SbDV-Y, SbDV-NZ, and SbDV-TAS, but not to BLRV, BWYV, and the nonluteo BMV (Table 1). Also, the MAbs reacted differentially to the endemic SbDV isolates tested (Table 2). MAb 1C6 bound all endemic isolates tested. MAb 1C9 bound all isolates except NY, and MAb 1F8 only bound isolates MD-2, VA 20, and NY. There was no reaction to healthy controls, and there was no difference between polyclonal antibody capture using antisera to either SbDV-D or SbDV-Y (Table 2).

Immunoblot analysis. All isolates except BWYV reacted with SbDV-D antisera on Western blots (Fig. 2). Four isolates (SbDV-D, SbDV-Y, MD-2, and VA 20) exhibited a 26-kDa coat protein band, and BLRV exhibited a $27-\mathrm{kDa}$ protein band. The BLRV isolate exhibited weak cross-reactivity with SbDV-D antisera. A 51- to 52-kDa protein band was visible with SbDV-D, SbDV-Y, and VA 20, but not with BLRV. The MD-2 isolate exhibited a much less intense 51 - to 52-kDa protein band, but had additional 44- and 31-kDa bands.

dsRNA analysis. Gel profiles of dsRNA preparations of SbDV-D, SbDV-Y, the endemic isolates, and BLRV are shown in Figure 3; BMV and tobacco mosaic virus (TMV) are known size markers. All luteovirus isolates exhibited two distinct bands representing the genomic and subgenomic dsRNAs. The genomic and subgenomic bands for SbDV-Y are slightly larger than those of SbDV-D. Among the endemic isolates, the genomic and subgenomic dsRNAs of isolates NY, PA, SC, and VA 20 appear to be similar to SbDV-D, and those from the MD-1, MD-2, MS, KY, and NC isolates are more like SbDV-Y. The genomic and subgenomic BLRV dsRNAs (Fig. 3, barely visible) were consistently larger than those of the other isolates.
Northern blot hybridization analysis. Nucleic acid hybridization of the pSbDV-Y13 cDNA probe with both genomic and subgenomic RNAs of SbDV-D, SbDV-Y, and nine endemic luteovirus isolates is illustrated in Figure 4. The pSbDV-Y13 probe hybridized strongly to both genomic and subgenomic RNAs of SbDV-Y, MD-1, MD-2, MS, and KY and weakly to the genomic RNAs of SbDV-D, NC, NY, PA, SC, and VA 20 isolates. There was no hybridization to BLRV, indicating a lack of homology between the 3' ends of the SbDV-Y and BLRV genomes.

\section{DISCUSSION}

All the luteoviruses isolated from subterranean, white, red, and alsike clovers produced reddening of subterranean clover leaf margins, were transmitted by Acyrthosiphon pisum in a persistent manner, reacted to SbDV polyclonal and monoclonal antibodies, produced dsRNA profiles similar to SbDV-D or SbDV-Y, hybridized to a SbDV-Y 3' probe, and had coat proteins that reacted to antibodies raised against the SbDV-D coat protein.

Specific SbDV-Y MAb reactivity data indicate that none of the endemic isolates tested share the identical array of epitopes as the previously characterized Japanese and Australasian SbDV strains (7).

Immunoblot analyses using SbDV-D polyclonal antisera indicated that the coat proteins of isolates MD-2 and VA 20 were very similar to SbDV-D or SbDV-Y, but not to BLRV or BWYV. The SbDV-D, SbDV-Y, and VA 20 isolates produced distinctive 51- to $52-\mathrm{kDa}$ bands that may represent the readthrough protein. The less intense 51- to 52-kDa band and the two additional 44- and 31-kDa bands seen with the MD-2 isolate could possibly be the result of proteolytic cleavage of the readthrough protein during isolation. Similarly, the weak $21-\mathrm{kDa}$ protein band exhibited by SbDV-D (SbDV-Y, MD-2, and VA 20) is likely associated with partial proteolysis of coat protein. The BLRV coat protein was weakly crossreactive against the SbDV-D antiserum (Fig. 2), but no readthrough

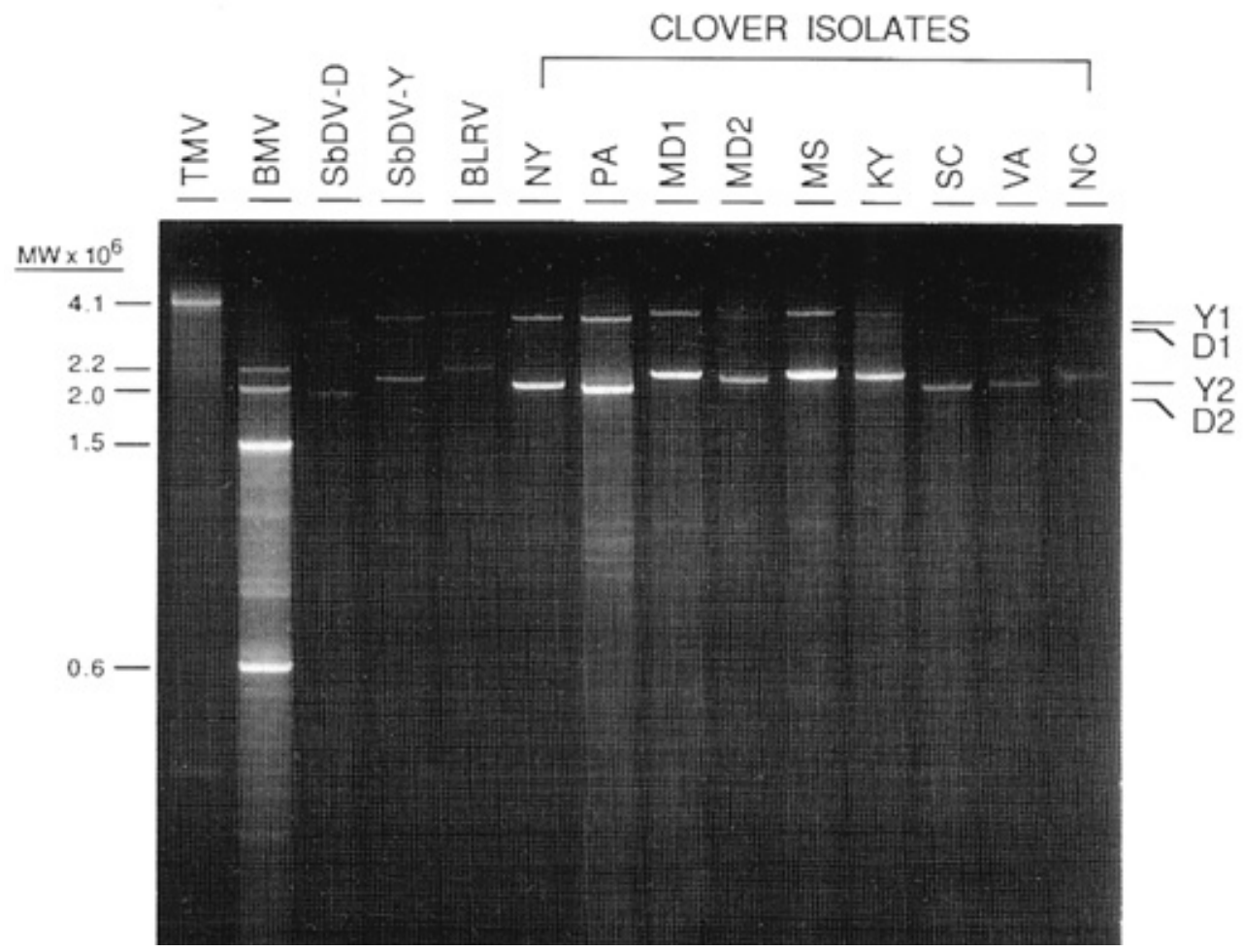

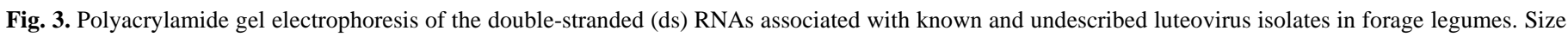

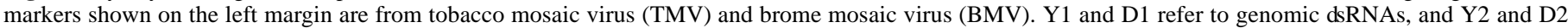

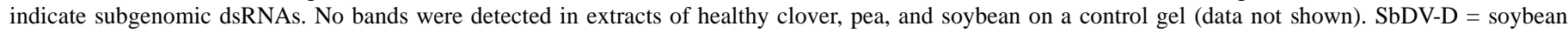

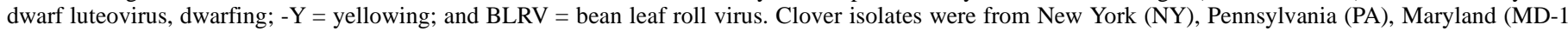
and MD-2), Mississippi (MS), Kentucky (KY), South Carolina (SC), Virginia (VA), and North Carolina (NC). 
protein band was evident. Also, BLRV was not detectable with the 2.2-kbp 3' SbDV-Y probe, which includes the readthrough protein gene (Fig. 4). The absence of either coat protein or readthrough bands by BWYV indicates a lack of relatedness to SbDV.

Examination of dsRNA profiles and northern blot hybridization analyses indicates that sizes of genomic and subgenomic RNAs of endemic isolates are similar to those of either SbDV-D or SbDV-Y. Based on mobility of genomic and subgenomic RNAs in polyacrylamide gels, there appear to be two populations of endemic isolates that are more similar to either SbDV-D (NY, PA, SC, and VA 20) or SbDV-Y (MD-1, MD-2, MS, KY, and NC). Host-range studies $(5,33)$ have shown that SbDV-Y infects white clover asymptomatically but not red clover; SbDV-D infects red clover but not white clover; and both infect other clovers. The MD-1, MD-2, MS, $\mathrm{KY}$, and $\mathrm{NC}$ isolates came from white clover, and the remaining isolates came from red, alsike, and subterranean clovers.

Luteoviruses exist as vector-specific and nonspecific strains (39). The SbDV type strains SbDV-D and SbDV-Y, transmitted specifically by A. solani, have been reported from Japan only. Related strains from New Zealand and Tasmania (SbDV-NZ and SbDVTAS, respectively) are transmitted by either A. solani or Acyrthosiphon pisum, but not by both. The endemic isolates are transmitted by Acyrthosiphon pisum $(7,8,23,24)$, but not by A. solani. Preliminary transmission data with Myzus persicae (Sulzer) has indicated it may transmit several of the endemic isolates in a persistent manner. Whether that indicates vector-nonspecific strains or a mixture of vector-specific strains remains to be determined.

We have found more than $25 \%$ of symptomless white clover from 11 states in the southeastern United States to be infected with SbDV, based on reaction to SbDV antisera (7). Others $(14,24)$ have found high levels of SbDV infection in white clover and subterranean clover; in Japan, white clover acts as the overwintering host of SbDV (35).

In Japan, where soybean dwarf is a serious disease of soybean, the migratory generation of the oriental biotype of $A$. solani acquires the virus before leaving white clover, its primary host, and flies to soybeans, its secondary host. This results in high levels of infection in soybean by virus strains that are highly virulent to soybean $(16,33)$. There are no aphid species in the western world or Australasia that colonize soybean (5). We were able to infect 'Williams' soybean with several endemic isolates utilizing Acyrthosiphon pisum (also M. persicae; V. D. Damsteegt, and A. L. Stone, unpublished data) under artificial conditions, producing very mild symptoms resembling those of SbDV-D or SbDV-Y. We occasionally observe soybean plants growing near forage legumes with typical SbDV-like symptoms; however, we have never observed spread beyond the border of a soybean field.

SbDV appears to be common in white clover in many areas of the world. Similar to barley yellow dwarf luteovirus (BYDV), which was named for the symptoms produced on barley from which it was first identified, soybean dwarf was named for soybean in Japan. Based on tradition, BYDV strains were named for the specific vector relationship (28), and SbDV strains were named for the symptoms produced in soybean (34). Rathjen et al. (27) used a geographic acronym, SbDV Tas-1, to identify an A. solani-transmitted isolate in Tasmania and SbDV AP-1 for an Acyrthosiphon pisumspecific strain. Although we have identified two populations of SbDV isolates in the United States, we propose to use one acronym for endemic isolates, SbDV-US, until further molecular characterization is conducted.

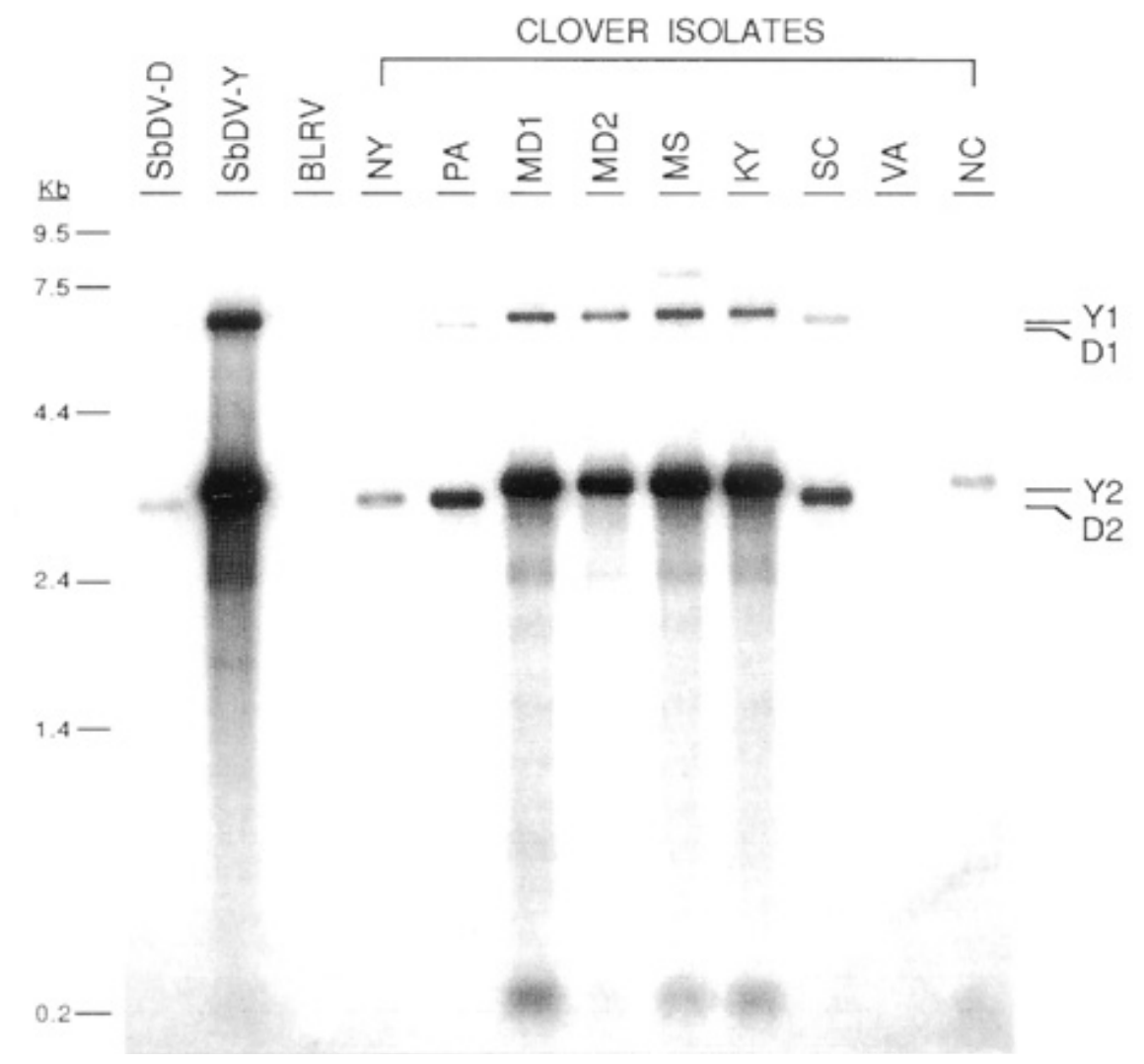

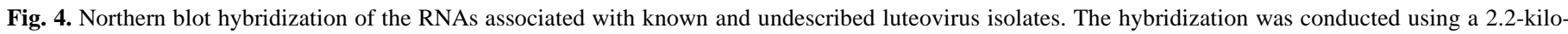

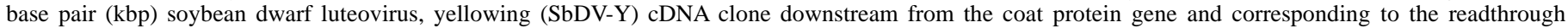

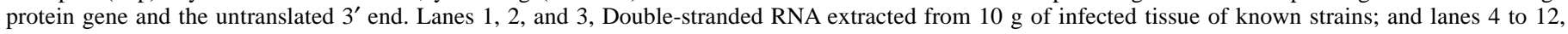

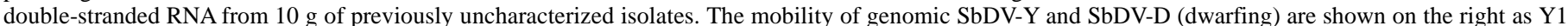

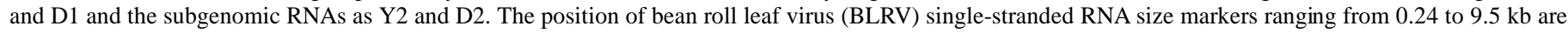

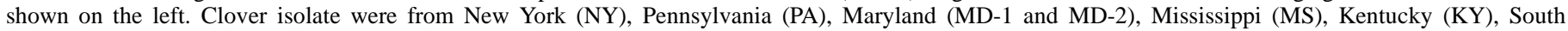
Carolina (SC), Virginia (VA), and North Carolina (NC). 


\section{ACKNOWLEDGMENTS}

We thank M. R. McLaughlin, O. W. Barnett, S. A. Tolin, C. L. Campbell, S. A. Ghabrial, T. Tamada, and R. O. Hampton for virus isolates; A. D. Hewings and S. A. Tolin for antisera; Brotherton Seed Company, Moses Lake, WA, for donation of 'Puget' pea seed for virus increase; C. Schmidt for purifying one of the isolates; and the many students whose diligent work has made this project possible.

\section{LITERATURE CITED}

1. Ashby, J. W. 1984. Bean leaf roll virus. Descriptions of Plant Viruses No. 286. Commonw. Mycol. Inst./Assoc. Appl. Biol., Kew, Surrey, England.

2. Ashby, J. W., The, P. B., and Close, R. C. 1979. Symptomatology of subterranean clover red leaf virus and its incidence in some legume crops, weed hosts, and certain alate aphids in Canterbury, New Zealand. N.Z. J. Agric. Res. 22:361-365.

3. Clark, M. F., and Adams, A. N. 1977. Characteristics of the microplate method of enzyme-linked immunosorbent assay for detection of plant viruses. J. Gen. Virol. 34:475-484.

4. Clark, M. F., Lister, R. M., and Bar-Joseph, M. 1986. ELISA techniques. Methods Enzymol. 118:742-766.

5. Damsteegt, V. D., Hewings, A. D., and Sindermann, A. B. 1990. Soybean dwarf virus: Experimental host range, soybean germ plasm reactions, and assessment of potential threat to U.S. soybean production. Plant Dis. 74:992-995.

6. Damsteegt, V. D., Russo, A. J., Stone, A. L., and Smith, O. P. 1992. Identification and relatedness of persistently aphid-transmitted virus isolates from forage legumes in the southeast United States. (Abstr.) Phytopathology 82:1144.

7. Damsteegt, V. D., Stone, A. L., and Hewings, A. D. 1995. Soybean dwarf, bean leaf roll, and beet western yellows luteoviruses in southeastern U.S. white clover. Plant Dis. 79:48-50.

8. Damsteegt, V. D., and Voegtlin, D. J. 1990. Morphological and biological variation among populations of Aulacorthum solani (Homoptera: Aphididae), the vector of soybean dwarf virus. Ann. Entomol. Soc. Am. 83:949-955.

9. D'Arcy, C. J., Martin, R. R., and Spiegel, S. 1990. A comparative study of luteovirus purification methods. Can. J. Plant Pathol. 11:251-255.

10. D'Arcy, C. J., Torrance, L., and Martin, R. R. 1989. Discrimination among luteoviruses and their strains by monoclonal antibodies and identification of common epitopes. Phytopathology 79:869-873.

11. Hewings, A. D., Damsteegt, V. D., Sindermann, A. E., and Tolin, S. A. 1990. Variations in serologically detectable antigen of soybean dwarf virus in soybean leaflets as a function of time after inoculation and plant age. Plant Dis. 74:844-848.

12. Hewings, A. D., Damsteegt, V. D., and Tolin, S. A. 1986. Purification and some properties of two strains of soybean dwarf virus. Phytopathology 76:759-763.

13. Johnstone, G. R., and Guy, P. L. 1986. Epidemiology of viruses persistently transmitted by aphids. Proc. Workshop Epidemiol. Plant Virus Dis., IX/1-IX/7. Int. Soc. Plant Pathol., Orlando, FL.

14. Johnstone, G. R., Liu, H.-Y., and Duffus, J. E. 1984. First report of a subterranean clover red leaf-like virus in the western hemisphere. (Abstr.) Phytopathology 74:795.

15. Johnstone, G. R., and McLean, G. D. 1987. Virus diseases of subterranean clover. Ann. Appl. Biol. 110:421-440.

16. Kanehira, O. 1978. Seasonal prevalence of foxglove aphid Acyrthosiphon solani (Kaltenbach) in soybean varieties-Differences in resistance to the soybean dwarf disease. Bull. Hokkaido Prefect. Agric. Exp. Stn. 40:51-60.

17. Kellock, A. W. 1971. Red-leaf virus-A newly recognized virus disease of subterranean clover (Trifolium subterraneum L.). Aust. J. Agric. Res.
22:615-624.

18. Kohler, G., and Milstein, L. 1975. Continuous cultures of fused cells, secreting antibody of predefined specificity. Nature 256:495-497.

19. Kojima, M., and Tamada, T. 1976. Purification and serology of soybean dwarf virus. Phytopathol. Z. 85:237-250.

20. Laemmli, U. K. 1970. Cleavage of structural proteins during the assembly of the head of bacteriophage T4. Nature 227:680-685.

21. Makkouk, K. M., Damsteegt, V., Johnstone, G. R., Katul, L., Lesemann, D.-E., and Kumari, S. G. 1997. Identification and some properties of soybean dwarf lutoeovirus affecting lentil in Syria. Phytopathol. Mediterr. 36:135-144.

22. Martin, R. R., and Stace-Smith, R. 1984. Production and characterization of monoclonal antibodies specific to potato leaf roll virus. Can. J. Plant Pathol. 6:206-210.

23. McLaughlin, M. R., Damsteegt, V. D., Duffus, J. E., and Hewings, A. D. 1988. Subterranean clover red leaf (soybean dwarf)-like luteovirus found in Mississippi. (Abstr.) Phytopathology 78:1584.

24. McLaughlin, M. R., Pederson, G. A., Evans, R. R., and Ivy, R. L. 1992. Virus diseases and stand decline in a white clover pasture. Plant Dis. 76: $158-162$.

25. Morris, T. J., and Dodds, J. A. 1979. Isolation and analysis of doublestranded RNA from virus-infected plant and fungal tissue. Phytopathology 69:854-858.

26. Rajeshwari, R., and Murant, A. F. 1988. Purification and particle properties of groundnut rosette assistor virus and production of a specific antiserum. Ann. Appl. Biol. 112:403-414.

27. Rathjen, J. P., Karageorgos, L. E., Habili, N., Waterhouse, P. M., and Symons, R. H. 1994. Soybean dwarf luteovirus contains the third variant genome type in the luteovirus group. Virology 198:671-679.

28. Rochow, W. F. 1969. Biological properties of four isolates of barley yellow dwarf virus. Phytopathology 59:1580-1589.

29. Russo, A. J., Keller, C., Beck, R. J., Smith, O. P., and Damsteegt, V. D. 1991. Production of monoclonal antibodies to the yellowing strain of soybean dwarf virus. (Abstr.) Phytopathology 81:703-704.

30. Sasagawa, R., and Kojima, M. 1994. Electron microscopy of soybean leaf phloem tissues infected with soybean dwarf virus. Bull. Fac. Agric. Niigata Univ. 46:13-20.

31. Smith, O. P., Damsteegt, V. D., Harris, K. F., and Vonder Haar, R. 1993. Nucleotide sequence and E. coli expression of the coat protein gene of the yellowing strain of soybean dwarf luteovirus. Arch. Virol. 133:223-231.

32. Smith, O. P., Hunst, P. L., Hewings, A. D., Stone, A. L., Tolin, S. A., and Damsteegt, V. D. 1991. Identification of dsRNAs associated with soybean dwarf virus-infected soybean. Phytopathology 81:131-134.

33. Tamada, T. 1970. Aphid transmission and host range of soybean dwarf virus. Ann. Phytopathol. Soc. Jpn. 36:266-274.

34. Tamada, T. 1973. Strains of soybean dwarf virus. Ann. Phytopathol. Soc. Jpn. 39:27-34.

35. Tamada, T. 1975. Studies on the soybean dwarf disease. Rep. Hokkaido Prefect. Agric. Exp. Stn. 25:1-144.

36. Tamada, T., Goto, T., Chiba, I., and Suwa, T. 1969. Soybean dwarf, a new virus disease. Ann. Phytopathol. Soc. Jpn. 35:282-285.

37. Tamada, T., and Kojima, M. 1977. Soybean dwarf virus. Descriptions of Plant Viruses No. 179. Commonw. Mycol. Inst./Assoc. Appl. Biol., Kew, Surrey, England.

38. Towbin, H., Staehelin, T., and Gordon, J. 1979. Electrophoretic transfer of proteins from polyacrylamide gels to nitrocellulose sheets: Procedure and some applications. Proc. Natl. Acad. Sci. U.S.A. 76:4350-4354.

39. Waterhouse, P. M., Gildow, F. E., and Johnstone, G. R. 1988. Luteovirus group. Descriptions of Plant Viruses No. 339 Commonw. Mycol. Inst./Assoc. Appl. Biol., Kew, Surrey, England.

40. Wilson, J., and Close, R. C. 1973. Subterranean clover red leaf virus and other legume viruses in Canterbury. N.Z. J. Agric. Res. 16:305-310. 